\title{
Simplification of urea treatment method of wheat straw for its better adoption by the farmers
}

\author{
M.A. Jabbar, H. Muzafar, F.M. Khattak ${ }^{1}$, T.N. Pasha" and A. Khalique \\ Department of Food \& Nutrition, University of Veterinary \& Animal Sciences, Lahore, 5300-Pakistan \\ ${ }^{1}$ Department of Poultry Production, University of Veterinary \& Animal Sciences, Lahore, 5300- Pakistan
}

\begin{abstract}
Limited use of cereal straws in livestock feeding is due to their low voluntary intake, low protein contents and low digestibility. Nutritional value of these roughages can be improved through chemical or physical methods. Efficacy of treating straw with urea for improving its nutritive value is considered equivalent to anhydrous or aqueous ammonia. However, the adoption rate of urea treatment by farmers is low, maybe due to relatively tedious technology and higher requirement of labour. There is need to simplify urea treatment methods. In the present study an effort has been made to simplify the existing urea treatment method so that farmers could easily adopt this technique. The new method involves weighing the required amount of urea (4\% of straw), mixing it with double the amount of farm manure (as urease source), giving $30 \%$ moisture by adding water, putting this mixture in a bag, piling the straw on the bag, again moistening the straw with water (50\% of straw) and incubating this material for a month under the cover of plastic sheet or mud plaster. In this method three steps including preparation of urea solution, sprinkling of solution on straw and pressing the straw during treatment process, have been eliminated which resulted in saving labour by $55 \%$. The efficiency of the new method, however, is about $30 \%$ less than the conventional urea treatment method.
\end{abstract}

Keywords: Urea treatment, wheat straw, urease enzyme, cow dung, simplification

\#Corresponding author. E-mail: agrotech@brain.net.pk

\section{Introduction}

In developing countries, livestock is usually fed high fibrous crop residues (wheat straw, rice straw, stovers, etc.) characterized by high indigestible fibre due to increased lignification of cellulose. Fermentable energy and protein deficiencies in crop residues coupled with their low digestibility impair intake, ruminal functions, and thus animal productivity. The situation strongly demands the improvement of the nutritive value of high fibrous crop residues through various treatments, for the efficient utilization of existing feed resources.

Efforts were made in the past to improve the digestibility and protein through chemical treatment. In this connection sodium hydroxide was used (Dass \& Kundu, 1994) which resulted in improving the digestibility, but its use remained limited due to a high cost of chemical and environmental pollution. The other compound used was anhydrous ammonia (Gotlib et al., 1977) which improved the digestibility and increased the nitrogen contents of the treated straw (Yadav \& Yadav, 1989), but non-availability of ammonia gas in the common market and its transportation through specialized containers limited its use. Lately fertilizer grade urea has been used for this purpose (Ali et al., 1992; Sarwar et al., 2006). Urea is cheaper, easily available and assumed to be equivalent to anhydrous or aqueous ammonia for upgrading cereal straws in the warmer regions of the world.

However, the adoption rate of this technique remained low. One reason may be the relatively tedious technology and high requirement of labour. There is a need for the method of treatment to be simplified, with minimum involvement of labour. O’Donovan et al. (1997) reported that the urea treatment process would be popular if it is simple, practical and the material to be used in the treatment is available on the farm. In the present study an effort was made to simplify the conventional urea treatment method by using urease enzyme sources available at the farm, so that farmers could easily adopt this technology. 


\section{Materials and Methods}

In the present study five laboratory trials and one large-scale trial were conducted. In these trials wheat straw along with urea, a urease source and water were mixed. This mixture was then put in a small (100 mm $\mathrm{x} 150 \mathrm{~mm}$ ) cloth bag which was placed at the bottom of a plastic jar, and the jar was then filled with straw. These jars were kept at room temperature $\left(29-30^{\circ} \mathrm{C}\right)$ for one month for the completion of the process. On completion of the incubation period, the wheat straw was taken out, mixed and tested for nitrogen contents (crude protein \%) using the Kjeldhal method (Harris, 1970).

In trial-1, 20 indigenous urease sources were tested for the urease activity in the laboratory using the method described by Gorin et al. (1962). These included acacia leaves, lucerne leaves, lobia beans, buffalo dung, soil wet with animal urine and sheep faeces, etc. Urease sources with urease activity more than 50 i.u. were incubated with urea for the treatment of straw and their efficiency for nitrogen binding was determined.

In trial-2, the optimum level of the enzyme source for mixing with urea was determined. Buffalo manure, having maximum urease activity, was selected as a urease source. Six different levels of manure (50, $100,150,200,250$ and $300 \%$ of urea) were tested.

In trial-3, 10 urea levels (1 - 10\%) were incubated with equal quantity of urease enzyme and crude protein of treated straw was determined for the optimum level.

In trial-4, the same protocol as in trial-1 was used for determining the level of moisture for the treatment of wheat straw. The only difference was in the level of water added to the wheat straw. The quantity of water varied from $10-100 \%$ of the straw to be treated.

In trial-5, eight samples were treated for optimization of length of incubation according to the conventional method while eight were treated using the new method. At the end of each week one jar from the conventional method and one from the new method were opened, and representative samples were tested for protein contents.

In trial-6, comparison of conventional and new methods at a larger scale was determined. The validity of results and performance of the newly developed method were tested at a larger scale by treating the straw in larger quantities in concrete pits. For this purpose four $1.2 \times 1.2 \times 1.2$ cemented pits were prepared. They had the capacity of holding one ton of wheat straw each. In pit No.1, dry straw was pilled up on the ureamanure bag. In pit No.2 water was mixed at $50 \%$ of the straw along with urea mixture. In pit No.3 water was increased to $100 \%$ of the straw. In pit No.4 straw was treated according to the conventional method which included sprinkling of straw with equal quantity of $4 \%$ urea solution. After incubation for one month the pits were opened and six samples from each pit were collected. These samples were then mixed and analyzed for protein content.

The data thus obtained were statistically analyzed using Completely Randomized Design (CRD) and means were compared by Duncan's Multiple Range (DMR) test (Steel et al., 1997) using the computer programme, M. STAT.

\section{Results and Discussion}

Among the urease sources tested, buffalo dung and acacia leaves had the highest urease activity (88 iu and $52 \mathrm{iu}$ ) and lentils the lowest. Buffalo dung alone and acacia leaves were used as enzyme source for fermenting the urea in the new method. Crude protein percentage of the treated straw was higher (10.27 vs. $6.85 \%)$ with buffalo dung than with acacia leaves $(\mathrm{P}<0.05)$. Coxworth \& Kullman $(1978)$ and Ali \& Naseer (1986) concluded that the use of buffalo dung as a source of urease enzyme, with double to the amount of urea for a period of four weeks at ambient temperature, was more economical and gave better results for practical purposes at farm level. In subsequent trials buffalo dung was used as urease source.

Results for the estimation of optimum level of enzyme source for mixing with urea (trial-2) showed that the crude protein value significantly $(\mathrm{P}<0.05$ ) increased from 4.69 to $6.42 \%$ when the level of buffalo dung as a urease source was increased from 50 to $150 \%$. These findings are supported by the results of Ali \& Naseer (1986) who concluded that use of buffalo dung as a source of urease, with double the amount of urea gave the best results for practical purposes at farm level. Jabbar (1994) reported that the urease source (buffalo dung) equal to the amount of urea gave maximum nitrogen binding. Considering the variability of urease in these urease sources and to avoid any possibility of urease limitation, it is suggested that the urea should be mixed with double the amount of the urease source such as dung.

In trial-3 for determining the optimum level of urea, it was seen that crude protein \% of treated straw gradually increased with the increase in level of urea. This trend was similar in both new and conventional 
methods. Maximum binding was at 10\% urea inclusion. Trach et al. (1998) reported that with increased urea levels and the longer treatment duration, the higher was the content of chemically fixed nitrogen $(\mathrm{P}<0.05)$. The protein percentage was higher by $30 \%$ in the conventional method as compared to the new method. Pasha \& Tahir (1985) reported that in the conventional method of urea treatment, 4\% of the urea has been fixed due to a better quality of the final product and the economics. Gupta et al. (1988) reported that use of urea up to $5 \%$ level of urea is safe, economical and had a significant $(\mathrm{P}<0.01)$ effect on increasing the crude protein content of wheat straw. Hence, to coincide with the conventional method, safety and for economic reason, $4 \%$ of urea was also fixed in new method.

Results on level of moisture for the treatment of wheat straw (trial-5) showed that, as the level of water was increased from 10 to $100 \%$, the protein content of straw increased from 3.3 to $9.68 \%$. These values were quite close to that of the conventional method where $100 \%$ water was used for the urea solution mixed with the straw. This indicated that addition of water is necessary for maximum enzyme activity. Although, it has been reported that urea treatment of straw is possible even with dry wheat straw, the protein percentage remains low, because the lower moisture level decreases the hydrolysis of urea to ammonia and binding of nitrogen to fibre (Hadjipanayiotou et al., 1993).

Length of incubation (trial-6) indicated that as it increased from one week to eight weeks the crude protein values also increased in both methods. The results were in agreement with the findings of Cloete \& Kritzinger (1984). The protein percentage in the conventional method was maximum at eight week (6.0\%) whereas in the new method the constant increasing trend was up to the fifth week (4.56\%), and after that it did not increase significantly. From this trend we can conclude that depending upon ambient temperature, an incubation period of four to six weeks is sufficient, with a minimum of four weeks. However, Hadjipanaiotou \& Economides (1997) reported that under Mediterranean conditions, treatment time of two weeks was required during summer month for maximum response.

The comparison of the conventional and new method on a larger scale (trial-6) indicated that the protein contents of the treated material in pits was lower than those obtained at laboratory scale. The reason may be that large amount of nitrogen escaped in the pits. Kamo \& Nakagawasai (1996) reported that the nutritive value of treated wheat straw increased with the air tightness of the storage container. The protein contents were lower in pit No.1 where only dry straw was added on the urea-manure mixture bag. The protein contents of the straw increased from 2.18 to $4.29 \%$ when water was added at $50 \%$ of the weight of the straw. The results obtained were in agreement with the findings of Hussain (1990). However, when 100\% water was added, there was no further improvement $(\mathrm{P}>0.05)$. Hence, addition of water up to $50 \%$ of straw was optimum.

Economic analysis showed that for treating $500 \mathrm{~kg}$ straw, the cost was $\$ 8.2$ vs. $\$ 3.7$ for the conventional and the new method, respectively, which showed that the cost could be reduced by up to $45 \%$ using the new method.

\section{Conclusions}

The new method of urea treatment of straw is simpler with less involvement of labour. However, for binding of nitrogen it is $30 \%$ less efficient than the conventional urea treatment method.

\section{References}

Ali, A. \& Naseer, Z., 1986. Nutritional evaluation of wheat straw treated with urea and ammonium bicarbonate using buffalo dung as urease source. Proc. $3^{\text {rd }}$ AAAP Animal Science Congress, Seoul, Korea.

Ali, A., Gilani, A.H. \& Khan, M.A., 1992. Digestibility of alkali and urea treated straw in sheep. J. Anim. Plant Sci. 2 (1-2), 19-20.

Cloete, S.W.P. \& Kritzinger, N.M., 1984. A laboratory assessment of various treatment conditions affecting the ammoniation of wheat straw by urea. 2 . The effect of temperature, moisture and incubation period. S. Afr. J. Anim. Sci. 14 (2), L 55-58.

Coxworth, E. \& Kullman, P., 1978. Improving the feeding value of straw and other forages by the use of ammonia released from urea by the action of an urease enzyme. Saskatchewan Research Council, C 78-14 (2), 6.

Dass, M.M. \& Kundu, S.S., 1994. Effects of calcium hydroxide, urea and calcium hypochloride treatment on composition and digestibility of wheat straw. Ind. J. Dairy Sci. 47 (1), 59-61. 
Gorin, G., Fuch, E., Butler, L., Chopra, S. \& Hersh, R., 1962. Some properties of urease. Biochem. 1, 911.

Gotlib, V.G., Kuzentsova, A.I., Gotlib, G.F., Ushakov, Y.U.A. \& Henke, A.N.I., 1977. Digestibility of a diet with ammoniated straw. Nutr. Abst. Rev. 47 (4).

Gupta, R.S., Saenger, S., Dahiya, S.S., Sikka, P., Chaudhry, V. \& Mudgal, V.D., 1988. Dry matter and protein degradability of ammonia treatment straw in the rumen of buffalo bullocks. Proc. II World Buffalo Congress, New Delhi, 400-404.

Hadjipanayiotou, M. \& Economides, S., 1997. Assessment of various treatment conditions affecting the ammoniation of long straw by urea. Livest. Res. Rural Dev. 9, 5, 1997.

Hadjipanayiotou, M., Verhaeghe, L., Goodchild, T. \& Shaker, B., 1993. Ammoniation of straw using urea, ammonia gas or ammonium hydroxide. Livest. Res. Rural Dev. 5, 3, 1993.

Harris, L.E., 1970. Nutrition Research Techniques for Domestic and Wild Animals. Vol. 1. Anim. Sci. Dept. Utah State University, Logan, Utah.

Hussain, H.J., 1990. Digestibility and nitrogen balance of urea treated wheat straw in buffaloes. M.Sc. thesis, Univ. of Agri., Faisalabad.

Jabbar, M.A., 1994. Simplification of urea treatment process. Annual Report, Livestock Production Research Institute, Bahadurnagar, Okara. pp. 71-72.

Kamo, M. \& Nakagawasai, H., 1996. Studies on the ammonia treatment techniques of cereal straw. Nutr. Abst. Rev. 56 (1), 556.

O’Donovan, P.B., Soomro. F.M., Wagennar. J.P., Rehman, S. \& Bukhari, F.A., 1997. Urea treatment of straw- Friendly system improved upon in Balochistan. Livest. Res. Rural Dev. 9, 5.

Pahsa, T.N. \& Tahir, M.S., 1985. Compaprative study on the feeding of urea treated versus untreated wheat straw in fattening of male buffalo calves. 6th Annual Report, Livestock Production Research Institute, Bahadurnagar, Okara.

Sarwar, M., Nisa, M., Hassan, Z. \& Shazad, M.A., 2006. Influence of urea molasses treated wheat straw fermented with cattle manure on chemical composition and feeding value for growing buffalo calves. Livest. Sci. 105 (1-3), 151-161.

Steel, R.G.D., Torrie, J.H. \& Dickey, D.A., 1997. Principles and Procedures of Statistics. A Biochemical Approach ( $3^{\text {rd }}$ ed.). Mc. Graw Hill Book Co Inc, New York, USA.

Trach, N.X., Dan, Cu X., Le Viet L.Y. \& Sundstol, F., 1998. Effect of urea concentration, moisture content, and duration of treatment on chemical composition of alkali treated rice straw. Livest. Res. Rural Dev. $10,1$.

Yadav, B.P. \& Yadav, I.S., 1989. Comparative study of ammoniated wheat and paddy straw on nutrient utilization and rumen fermentation in cattle. Indian J. Anim. Nutr. 6, 215-222. 